\title{
Inquérito soro-epidemiológico na Ilha de São Luis durante epidemia de dengue no Maranhão
}

\author{
Seroepidemiologic survey in São Luis Island, State of Maranhão, \\ Brazil, during a dengue fever epidemics
}

\author{
Pedro Fernando da C. Vasconcelos, José W.0. Lima, Maria L. Raposo, \\ Sueli G. Rodrigues, Jorge F.S. Travassos da Rosa, Sílvia M.C. Amorim, \\ Elizabeth S. Travassos da Rosa, Cleide M.P. Moura, \\ Niedja Fonseca e Amélia P.A. Travassos da Rosa
}

\begin{abstract}
Resumo Nos anos de 1995 e 1996, ocorreu em São Luis uma epidemia de dengue (DEN), causada pelo sorotipo DEN1. Objetivando avaliar o impacto da mesma na populacão da grande São Luis (municípios de Paço do Lumiar - PL, São José de Ribamar - SJR e São Luis SL), realizamos um inquérito soro epidemiológico aleatório, onde aplicamos um questionário. Os soros foram testados por inibição da hemaglutinação (IH), e os resultados, negativo e positivo (resposta primária - $R P$ e resposta secundária $R S)$, foram analisados utilizando os "software's" Lotus 123, Epi-info 6.0, Excel 5.0 e STATA. Coletaram-se 1217 amostras, (101 de PL, 100 de SJR e 1016 de SL). A positividade foi: $55,4 \%$ em PL, $28 \%$ em SJR e $41,4 \%$ em SL. Destes, 505 (41,2\%) amostras foram positivas sendo $96 R P(7,9 \%)$ e 405 RS (33,3\%). Da amostra obtida, 508 soros (227 positivos) foram do sexo masculino e 709 (278 positivos) do feminino, não havendo diferença estatística significativa. Houve significância $(p<0,003)$ na estratificação de acordo com a renda, sendo mais freqüente nas populações com melhor nível sócio econômico. Estimou-se em 401.933 infecções causadas pelo vírus dengue. Os pacientes referiram febre, cefaléia, calefrios, tontura, astenia, dor retro ocular, mialgia, artralgia, náuseas, anorexia, prurido e exantema. Há uma grande população sensibilizada pelo DEN-1, suscetível a outro sorotipos o que aumenta o risco de dengue hemorrágico.
\end{abstract}

Palavras-chaves: Dengue. Epidemia. Inquérito soro epidemiológico aleatório. São Luis. Brasil.

\begin{abstract}
The Island of São Luis in the State of Maranhão, constituted by the municipalities of São Luis SL (835,428 inhabitants), São José de Ribamar - SJR (60,633 inhabitants) and Paço do Lumiar - PL (80,274 inhabitants), has been suffering dengue (DEN) fever epidemics since 1995, caused by DEN-1. In 1996, from August through October, an aleatory sero-epidemiologic survey was carried out in order to estimate the incidence of DEN infection and to analyze other clinical and epidemiological parameters. $A$ questionnaire was applied and serum samples were simultaneously obtained. Serum samples were tested by hemagglutination inhibition (HI). Results were analyzed using Lotus 123, Epi-info 6.0, Excel 5.0 and STATA softwares. A total of 1,217 serum samples were obtained (101 of PL, 100 of SJR and 1017 of SL). The rate of DEN was $55.4 \%$ in PL, $28 \%$ in SJR and $41.4 \%$ in SL, suggesting the occurrence of 401,933 infections. No difference was seen between males and females, but infection occurred more in the upper social class than in poor people $(p<0.003)$, and was more frequent in adults than in children $(p<0.0004)$. In SL, the incidence was stratified into seven sanitary districts (SD), and prevalence was found to range from $26.1 \%$ in SD4 to $56.8 \%$ in SD1 ( $0<0.0001$ ). Symptoms were more frequently reported by people whose HI was positive: they included fever, headache, chills, dizziness, retrobulbar pains, muscle and joint pains, nausea, anorexia and skin rash. In spite of the high incidence of infection, no hemorrhagic cases were reported.
\end{abstract}

Key-words: Dengue fever. Epidemic. Epidemiology. Serologic survey. São Luis Island. Maranhão State. Brazil.

Centro Colaborador da Organização Mundial da Saúde em Arboviroses e Laboratório de Referência Nacional de Arbovírus, Instituto Evandro Chagas, Belém, PA; Coordenação Regional da Fundação Nacional de Saúde no Estado do Ceará, Fortaleza, CE; Secretaria de Estado de Saúde do Maranhão e Coordenação Regional da Fundação Nacional de Saúde no Estado do Maranhão, São Luís, MA, Brasil. Apoio: Instituto Evandro Chagas, Fundação Nacional de Saúde, Secretaria de Saúde do Estado do Maranhão e FINEP(Financiadora de Estudos e Projetos).

Endereço para correspondência: Dr. Pedro Fernando da Costa Vasconcelos. Av. Almirante Barroso 492, $66090-000$ Belém, PA, Brasil. Fax: 5591 226-1284

Recebido para publicação em 27/2/98. 
O vírus dengue (DEN) tem causado extensas epidemias no Brasil, a partir de 1986 quando foi reintroduzido o sorotipo DEN1 no Estado do Rio de Janeiro, quatro anos após a ocorrência da primeira epidemia de dengue no Brasil com descrição clínica e laboratorial ocorrida em Boa Vista, Roraima em 1982, causada pelo DEN1 e DEN4 9 10. Rapidamente esse sorotipo se disseminou pelo País, tendo sido notificado milhares de casos principalmente nos estados das regiões Sudeste (Rio de Janeiro, São Paulo e Minas Gerais) e Nordeste (Alagoas, Bahia, Ceará e Pernambuco) 2711 . Em 1990, foi introduzido o sorotipo DEN2, mais uma vez a partir do Rio de Janeiro8. Já em 1991, o DEN2 foi responsável por epidemia de febre clássica no Estado de Tocantins ${ }^{15}$, e em 1994, ocasionou uma grande epidemia com casos hemorrágicos no Estado do Ceará14. Em 1994, casos de dengue ocorreram em diversos municípios do Estado do Maranhão, tendo a epidemia atingido em 1995 a capital, São Luis, e os demais municípios (Paço do Lumiar e São José de Ribamar) que compõem a llha de São Luis. As epidemias de dengue, nesse municípios ocorreram sob a forma de febre clássica. Considerando que o número de notificações não correspondia à expectativa das autoridades estaduais de saúde, e tendo em conta a necessidade de conhecer o impacto dessa epidemia na llha de São Luis, a Secretaria de Saúde do Estado, Secretaria Municipal de Saúde e Coordenação Regional da Fundação Nacional de Saúde solicitaram ao Instituto Evandro Chagas a realização de um inquérito soro-epidemiológico. Os objetivos do inquérito foram os seguintes: 1) conhecer a prevalência da epidemia nos municípios afetados; 2) estimar o número de infecções causadas pelo vírus dengue; 3) avaliar a distribuição dos casos por sexo e faixa etária na população alvo do estudo; e 4) estratificar a ocorrência de casos entre as diferentes classes sócio-econômicas e graus de instrução.

Neste trabalho, descrevemos os principais achados do inquérito soro epidemiológico aleatório realizado na Ilha de São Luis.

\section{MATERIAL E MÉTODOS}

Descrição da metodologia. A metodologia empregada foi o desenho de um inquérito soro epidemiológico aleatório. Apopulação estudada, 976.335 habitantes, correspondeu a estimada pelo IBGE para o ano de 1996 compreendendo os residentes dos municípios de Paço do Lumiar $=60.633$ habitantes; São José de Ribamar $=80.274$ habitantes; São Luis $=835.428$ habitantes.de São Luis, que se encontram dentro da llha de São Luis. O sorteio foi feito em computador utilizando o software Lotus $123^{\circledR}$. Após o sorteio, sabia-se a casa do paciente. No local, listava-se os residentes do domicílio e imediatamente sorteava-se o indivíduo a ter seu sangue coletado. Somente um indivíduo por domicílio era sorteado para coletar sangue. Antes da coleta, um questionário contendo informações gerais (de identificação), sobre antecedentes de doença sugestiva de dengue, e dados sócioeconômicos, foi aplicado. Os dados do questionário e os resultados sorológicos foram armazenados numa planilha eletrônica preparada no software Microsoft "Excel'®, EUA. As análises dos resultados foram realizadas utilizando os software's "Excel"® e Adobe "Stata" ${ }^{\circledR}$, EUA. A amostra foi desenhada para conter uma precisão de $95 \%$ com risco relativo (perdas) e erro $\alpha$ de $5 \%$. Utilizou-se como parâmetros para estimar a população, os dados da Coordenação Regional da Fundação Nacional de Saúde no Maranhão.
Coleta das amostras. As amostras de sangue foram obtidas utilizando o método a vácuo sem anticoagulante. De cada indivíduo sorteado, coletou-se $5-10 \mathrm{ml}$ de sangue, sendo imediatamente acondicionado em caixas térmicas de isopor até a chegada no Laboratório Central (LACEN) de São Luis. Os soros foram separados e armazenados em tubos plásticos tipo Eppendorf e refrigerados em freezer a $-20^{\circ} \mathrm{C}$, até a realização dos exames sorológicos em Belém.

Teste sorológico. O teste sorológico empregado foi a inibição da hemaglutinação (IH), utilizando a técnica de Clarke \& Casals modificada12. Este teste é ótimo para inquéritos, posto que permite a identificação de todas as infecções causadas pelo dengue, recentes e/ou passadas, uma vez que dosa anticorpos totais. Os resultados, em $\mathrm{IH}$, foram classificados em negativo e positivo para Flavivirus (neste caso, pode ser considerado como resposta primária, específica para dengue 1 ou resposta secundária, quando são detectados anticorpos IH para diversos vírus do mesmo gênero).

Infecção prévia por dengue. A todos os pacientes incluídos no inquérito, foi perguntado sobre a ocorrência de infecção prévia por dengue, e quais os sintomas por ventura apresentados. Assim tivemos no inquérito, dois grupos: pessoas 
que relataram nunca ter adoecido com dengue e outro grupo formado pelas que relataram já ter adoecido com dengue. Esses dados foram importantes para comparar a positividade com as informações dos pacientes, e serviu de base para se calcular as infecções assintomáticas.

\section{RESULTADOS}

Amostras do estudo. Foram coletadas 1.217 amostras de soro nos três municípios, distribuídas com segue: 100 em Paço do Lumiar (PL); 101 em São José de Ribamar (SJR) e 1.016 em São Luis. A prevalência global de anticorpos encontrada na llha de São Luis foi de $41,5 \%$ o que corresponde a ocorrência de aproximadamente 401.933 infecções (Figura 1).

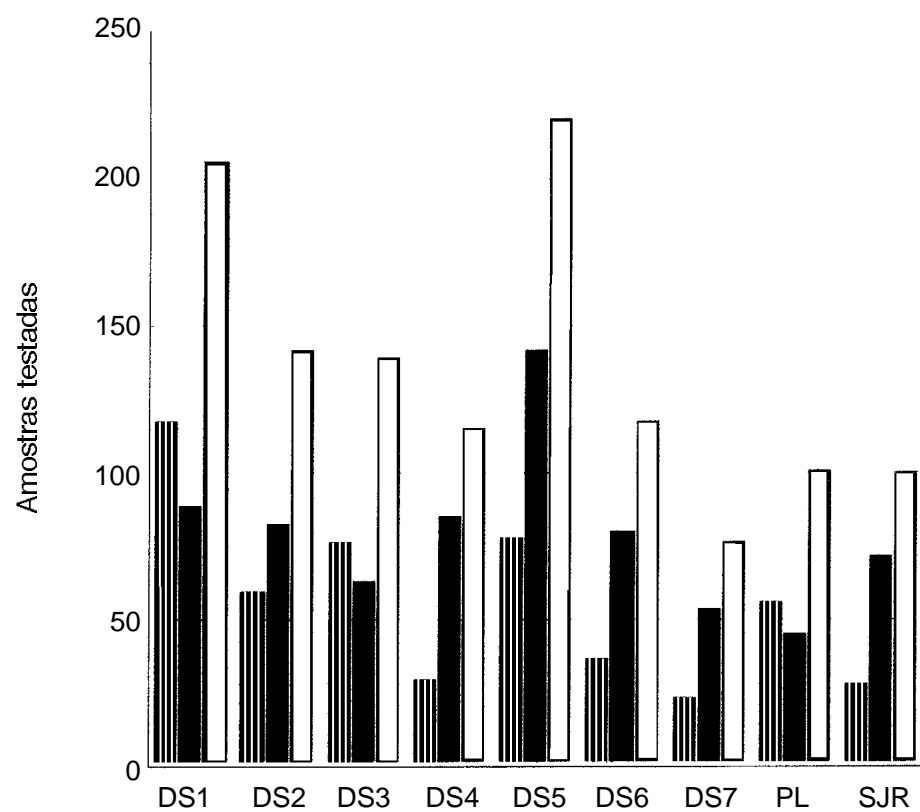

Distrito santiário |ll| Positivo

Negativo

Total

Figura 1 - Inquérito soro-epidemiológico na Ilha de São Luis. Distribuição das amostras testadas por distrito sanitário.

Paço do Lumiar. Foram colhidas 101 amostras de soro desse município. Desse total, houve positividade de $55,4 \%$. Considerando a população desse município (60.633 habitantes), essa prevalência indica a ocorrência de 33.590 infecções.

São José de Ribamar. Nesse município foram coletadas 100 amostras sorológicas. A população de São José de Ribamar durante o inquérito era de 80.274 habitantes. Apositividade das amostras estudadas foi de $28 \%$. Considerando essa prevalência, podemos estimar que ocorreram cerca de 22.476 infecções.
São Luis. A situação da capital maranhense é mais complexa, tendo em consideração sua maior população, cerca de 835.428 habitantes. Esta foi distribuída em sete distritos sanitários que apresentam densidades populacionais e características sócio econômicas diferentes. A distribuição da prevalência de anticorpos nos distritos sanitários variou de $29,9 \%$ no DS7 a $56,8 \%$ no DS1. Considerando a prevalência média de $41,4 \%$, estimamos a ocorrência de 345.867 infecções (Tabela 1).

Sexo. Das 1.217 amostras coletadas, 508 $(41,7 \%)$ foram procedentes de indivíduos do 
sexo masculino e 709 (58,3\%) do sexo feminino. A prevalência global em indivíduos do sexo masculino foi de $44,7 \%$ (227) e de $39,2 \%$ (278) no sexo feminino. Esses resultados não apresentaram significância estatística mostrando que o risco de transmissão do dengue foi similar entre as amostras positivas de ambos os sexos na llha de São Luis.

Tabela 1 - Distribuição das amostras coletadas nos municípios de São Luis (DS1 a DS7), Paço do Lumiar (PL) e São José do Ribamar (SJR) de acordo com o resultado do exame.

\begin{tabular}{|c|c|c|c|c|c|c|}
\hline \multirow[t]{2}{*}{ Distritos sanitários } & \multicolumn{2}{|c|}{ Amostras positivas } & \multicolumn{2}{|c|}{ Amostras negativas } & \multicolumn{2}{|c|}{ Total testado } \\
\hline & $\mathrm{n}^{0}$ & $\%$ & $\mathrm{n}^{0}$ & $\%$ & $\mathrm{n}^{0}$ & $\%$ \\
\hline DS 1 & 117 & 56,8 & 89 & 43,2 & 206 & 16,9 \\
\hline DS 2 & 60 & 42,2 & 82 & 57,8 & 142 & 11,7 \\
\hline DS 3 & 76 & 54,7 & 63 & 45,3 & 139 & 11,4 \\
\hline DS 4 & 30 & 26,1 & 85 & 73,9 & 115 & 9,5 \\
\hline DS 5 & 78 & 35,5 & 142 & 64,5 & 220 & 18,1 \\
\hline DS 6 & 37 & 31,6 & 80 & 68,4 & 117 & 9,6 \\
\hline DS 7 & 23 & 29,9 & 54 & 70,1 & 77 & 6,3 \\
\hline PL & 56 & 55,4 & 45 & 44,6 & 101 & 8,3 \\
\hline SJR & 28 & 28,0 & 72 & 72,0 & 100 & 8,2 \\
\hline Total & 421 & 41,4 & 595 & 58,6 & 1016 & 100,0 \\
\hline
\end{tabular}

$\chi^{2} 6 \mathrm{GL}=53,40 ; \mathrm{p}<0,0001$

DS: Distrito sanitário

Renda. A distribuição das amostras testadas de acordo com a renda, nos mostra que a maioria, $56 \%$, procedeu de indivíduos com renda familiar entre um a três salários mínimos. Entretanto, a positividade foi maior nas classes com maior poder aquisitivo. A prevalência de anticorpos para dengue foi mais elevada na faixa entre três a cinco salários mínimos, com positividade de $51,7 \%$ dos soros testados, seguida da faixa que englobou indivíduos com renda familiar maior que cinco salários mínimos com 44,2\% (Tabela 2). Esses resultados quando montados em gráfico

Tabela 2 - Distribuição da positividade dos soros de acordo com a renda familiar.

\begin{tabular}{|c|c|c|c|c|c|c|}
\hline \multirow[t]{2}{*}{ Renda (SM) } & \multicolumn{2}{|c|}{ Positivo } & \multicolumn{2}{|c|}{ Negativo } & \multicolumn{2}{|c|}{ Total testado } \\
\hline & $\mathrm{n}^{0}$ & $\%$ & $\mathrm{n}^{0}$ & $\%$ & $\mathrm{n}^{0}$ & $\%$ \\
\hline$<1 \mathrm{SM}$ & 15 & 31,2 & 33 & 68,8 & 48 & 3,9 \\
\hline 1-3 SM & 283 & 38,4 & 453 & 61,6 & 736 & 60,5 \\
\hline 3-5 SM & 108 & 51,7 & 101 & 48,3 & 209 & 17,2 \\
\hline$>5 \mathrm{SM}$ & 99 & 44,2 & 125 & 55,8 & 224 & 18,4 \\
\hline Total & 505 & 41,5 & 712 & 58,5 & 1217 & 100,0 \\
\hline
\end{tabular}

$\chi^{2}=14,48 ; p<0,003$

SM: Salário mínimo

em barra, mostram claramente que o dengue na Ilha de São Luis, ocorreu principalmente nas classes sócio-econômicas com maior poder aquisitivo, apresentando inclusive significância estatística: $\chi^{2} 3 G L=14,48$ com $p<0,003$ (Figura 2).

Escolaridade. Aamostra coletada, 1217 soros, foi distribuída de acordo com a escolaridade do chefe da família em cinco níveis, a saber: a) nível I - analfabetos (4,4\% do total coletado); b) nível II - primeiro grau menor ou seja até $4^{\mathrm{a}}$ série do $1^{\circ}$ grau $(37,6 \%)$; c) nível III - primeiro grau maior ou seja $1^{\circ}$ grau completo $(20,7 \%)$; d) nível IV - segundo grau (28\%); e e) nível V - grau universitário $(9,3 \%)$. A positividade foi maior no nível IV com 33,4\% de todas as amostras positivas. Considerando cada faixa, a maior positividade ocorreu também no nível IV com 169 soros em 341 coletados, o que corresponde a uma prevalência de $49,6 \%$. A estratificação de todos os níveis pode ser vista, na Tabela 3. 


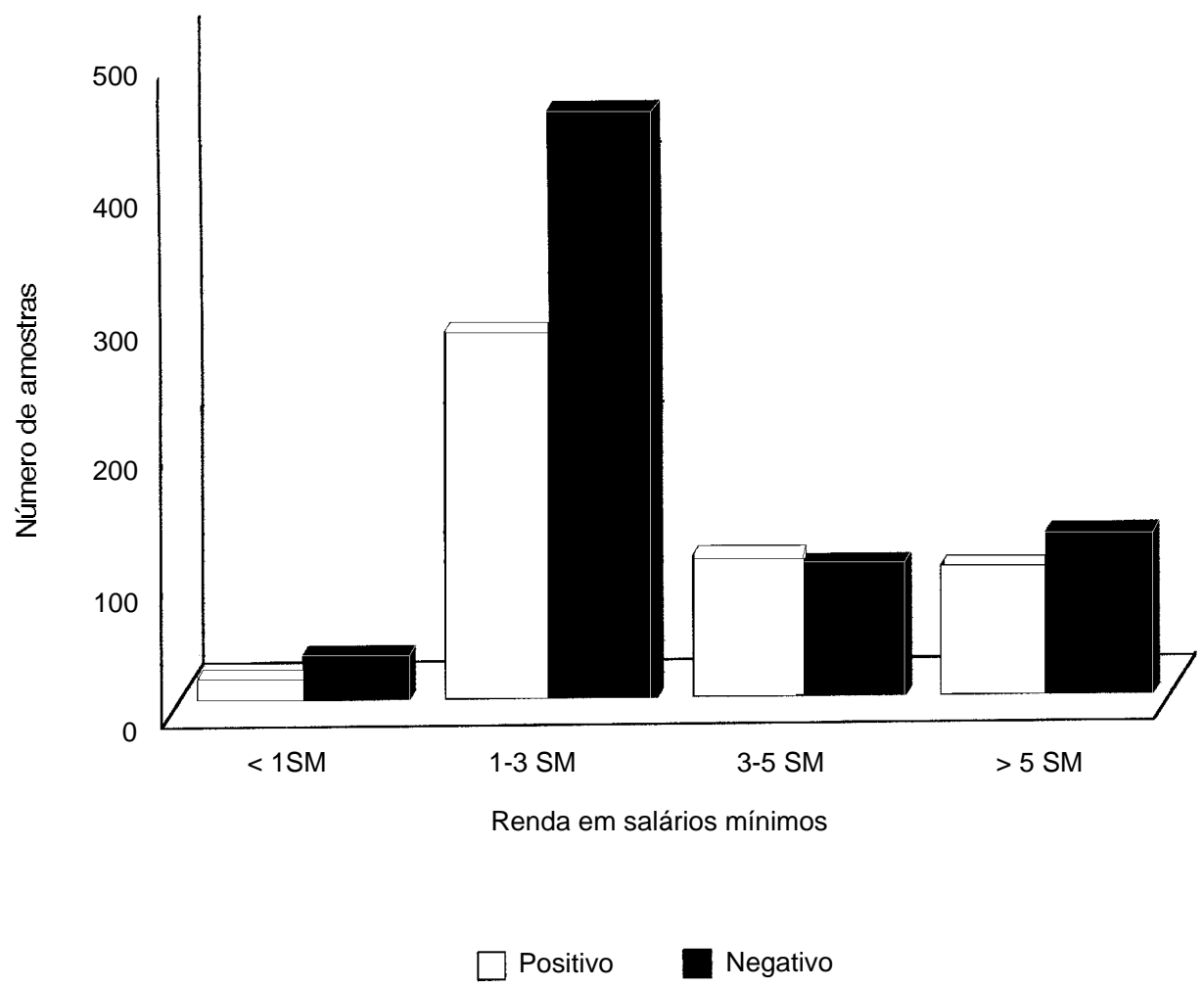

Figura 2 - Inquérito soro-epidemiológico na Ilha de São Luis. Distribuição dos casos de acordo com a renda familiar.

Tabela 3 - Distribuição das amostras do inquérito soro-epidemiológico de acordo com a escolaridade.

\begin{tabular}{|c|c|c|c|c|c|c|}
\hline \multirow[t]{2}{*}{ Escolaridade } & \multicolumn{2}{|c|}{ Positivo } & \multicolumn{2}{|c|}{ Negativo } & \multicolumn{2}{|c|}{ Testado } \\
\hline & $\mathrm{n}^{0}$ & $\%$ & $\mathrm{n}^{0}$ & $\%$ & $\mathrm{n}^{0}$ & $\%$ \\
\hline Analfabeto & 21 & 39,6 & 32 & 60,4 & 53 & 4,4 \\
\hline $1^{\circ}$ grau menor & 157 & 34,3 & 301 & 65,7 & 458 & 37,6 \\
\hline $1^{\circ}$ grau maior & 114 & 45,2 & 138 & 54,8 & 252 & 20,7 \\
\hline $2^{\circ}$ grau & 169 & 49,6 & 172 & 50,4 & 341 & 28,0 \\
\hline Grau universitário & 44 & 38,9 & 69 & 61,1 & 113 & 9,3 \\
\hline Total & 505 & 41,5 & 712 & 58,5 & 1217 & 100,0 \\
\hline
\end{tabular}

$\chi^{2}=20,79 ; p<0,0004$

Essa distribuição é melhor comparada em gráfico em barras verticais, mostrado a seguir (Figura 3). Percebe-se que, a positividade foi maior nos soros em que os responsáveis possuíam o $2^{\circ}$ grau, seguido do $1^{\circ}$ grau maior (completos). A Estratificação está bem evidenciada na Figura 3. Como pode ser observado, a variação da positividade apresentou significância estatística: $\chi^{2} 4 \mathrm{GL}=20,79 \mathrm{com}$ $\mathrm{p}<0,0004$.
Idade. A ocorrência de dengue na ilha de São Luis não foi uniforme no tocante à faixa etária, sendo altamente influenciada pela idade dos pacientes. Os indivíduos foram separados em faixas etárias, sendo menores de 15 anos, de 15-24 anos, 25-34 anos, 35-44 anos, 45-54 anos e maiores de 54 anos de idade. A prevalência da infecção foi menos freqüente em menores de 15 anos com $23,6 \%$, aumentando gradualmente com a idade, sendo muito elevada em maiores 


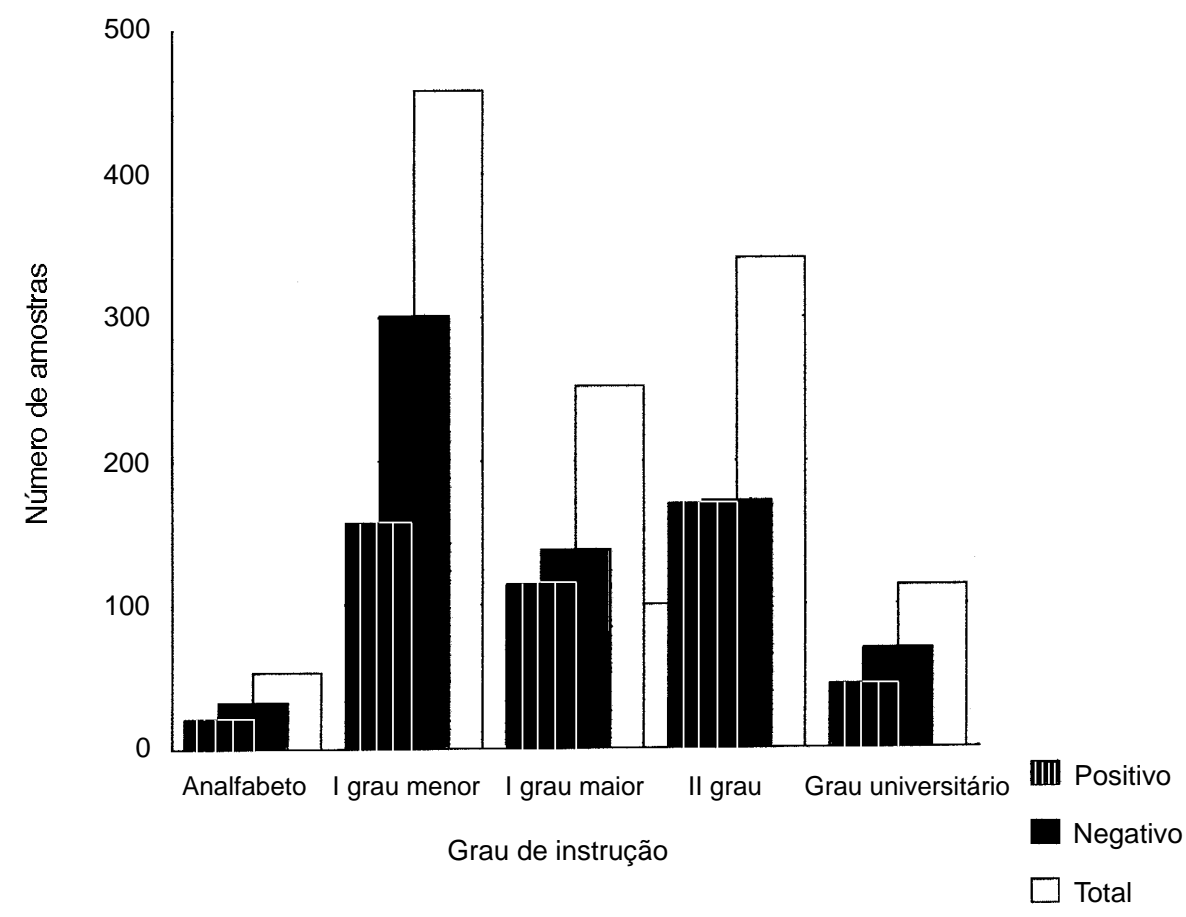

Figura 3 - Inquérito soro-epidemiológico na Ilha de São Luis. Ocorrência de casos de acordo com o nível de escolaridade.

de 55 anos cuja positividade foi de $55,2 \%$ da amostra testada. Essa apresentação quando submetida ao teste do qui-quadrado foi estatisticamente significante tendo $\chi^{2}=31,85$ com $\mathrm{p}<0,00001$ (Tabela 4).

Correlação presença de anticorpos $x$ sintomatologia apresentada. Das 1217 amostras colhidas, 501 foram positivas para dengue quanto a presença de anticorpos IH. Desse total, 187
$(37,3 \%)$ pacientes efetivamente afirmaram ter adoecido de dengue, ao passo que a maioria, ou seja, $314(62,7 \%)$ pessoas com anticorpos para dengue negaram ter contraído a doença. Por outro lado, 289 pessoas sorteadas no inquérito relataram ter adoecido de dengue, mas somente $187(64,7 \%)$ efetivamente apresentaram positividade nos exames sorológicos. Dessa forma, 102 (35,3\%), adoeceram de outras causas que não o dengue.

Tabela 4 - Distribuição da prevalência de anticorpos para dengue de acordo com a faixa etária, durante inquérito soro epidemiológico aleatório em Paço do Lumiar, São José de Ribamar e São Luis, Estado do Maranhão, 1996.

\begin{tabular}{|c|c|c|c|c|c|c|c|c|}
\hline \multirow{2}{*}{$\begin{array}{l}\text { Idade } \\
\text { (anos) }\end{array}$} & \multicolumn{2}{|c|}{ Negativo } & \multicolumn{2}{|c|}{$\mathrm{RP}$} & \multicolumn{2}{|c|}{$\mathrm{RS}$} & \multicolumn{2}{|c|}{ Testado } \\
\hline & $n^{0}$ & $\%$ & $\mathrm{n}^{0}$ & $\%$ & $\mathrm{n}^{\circ}$ & $\%$ & $\mathrm{n}^{0}$ & $\%$ \\
\hline$\leq 14$ & 110 & 76,4 & 11 & 7,6 & 23 & 16,0 & 144 & 11,8 \\
\hline $15-24$ & 207 & 60,0 & 28 & 8,1 & 110 & 31,9 & 345 & 28,3 \\
\hline $25-34$ & 176 & 59,0 & 27 & 9,1 & 95 & 31,9 & 298 & 24,5 \\
\hline $35-44$ & 99 & 54,4 & 12 & 6,6 & 71 & 39,0 & 182 & 15,0 \\
\hline $45-54$ & 59 & 57,3 & 5 & 4,8 & 39 & 37,9 & 103 & 8,5 \\
\hline$\geq 55$ & 65 & 44,8 & 13 & 9,0 & 67 & 46,2 & 145 & 11,9 \\
\hline Total & 716 & 58,8 & 96 & 7,9 & 405 & 33,3 & 1217 & 100,0 \\
\hline
\end{tabular}

$\chi^{2}=31,85 ; p<0,00001$

RP: Resposta primária para Flavivirus; RS: Resposta secundária para Flavivirus. 
O quadro clínico relatado pelos 187 pacientes que afirmaram ter adoecido de dengue e cujos exames foram positivos, foi compatível com febre clássica do dengue, onde além da febre elevada de início abrupto, os sintomas mais freqüentes apresentados foram cefaléia, mialgias, artralgias, dor retro ocular, calefrios, astenia, tontura, prurido e exantema. A distribuição das freqüências dessa sintomatologia é vista na Tabela 5.

Tabela 5 - Quadro clínico de pacientes com febre que apresentaram sorologia positiva e negativa para dengue, durante inquérito soroepidemiológico aleatório em Paço do Lumiar, São José de Ribamar e São Luis, Estado do Maranhão, 1996.

\begin{tabular}{|c|c|c|c|c|c|c|c|}
\hline \multirow[t]{2}{*}{ Sintomatologia } & \multicolumn{2}{|c|}{$\mathrm{RP}$} & \multicolumn{2}{|c|}{$\mathrm{RP}$} & \multicolumn{2}{|c|}{ Amostras negativas } & \multirow{2}{*}{$\begin{array}{c}\text { Pacientes } \\
n^{\circ}\end{array}$} \\
\hline & $\mathrm{n}^{\circ}$ & $\%$ & $\mathrm{n}^{\circ}$ & $\%$ & $\mathrm{n}^{\circ}$ & $\%$ & \\
\hline Mialgias & 34 & 12,8 & 143 & 53,8 & 89 & 33,4 & 266 \\
\hline Cefaléia & 32 & 12,7 & 133 & 53,0 & 86 & 34,3 & 251 \\
\hline Artralgia & 32 & 12,9 & 136 & 54,8 & 80 & 32,3 & 248 \\
\hline Astenia & 30 & 12,2 & 129 & 52,2 & 88 & 35,6 & 247 \\
\hline Dor retro-ocular & 30 & 12,8 & 125 & 53,4 & 79 & 33,8 & 234 \\
\hline Calafrios & 26 & 11,9 & 118 & 53,9 & 75 & 34,2 & 219 \\
\hline Tontura & 17 & 11,2 & 86 & 56,6 & 49 & 32,2 & 152 \\
\hline Prurido & 17 & 11,2 & 91 & 60,3 & 43 & 28,5 & 151 \\
\hline Exantema & 19 & 14,4 & 81 & 61,4 & 32 & 24,2 & 132 \\
\hline Vômitos & 8 & 14,1 & 28 & 49,1 & 21 & 36,8 & 57 \\
\hline Dor abdominal & 6 & 11,3 & 25 & 47,2 & 22 & 41,5 & 53 \\
\hline Diarréia & 9 & 20,0 & 19 & 42,2 & 17 & 37,8 & 45 \\
\hline
\end{tabular}

$\chi^{2}=7,22 ; p>0,5$

RP: Resposta primária para Flavivirus; RS: Resposta secundária para Flavivirus

\section{DISCUSSÃO}

A ocorrência de epidemias de dengue no Estado do Maranhão é recente, mormente a presença dos sorotipos DEN1 e DEN2. Quando da realização do inquérito soro epidemiológico aleatório, apenas o DEN1 ocorria na llha de São Luis. A importância do inquérito é, não somente a quantificação dos casos ocorridos a partir de 1995 a 1996, nos municípios que compõem a área metropolitana de São Luis, mas sobretudo, demonstrar a sub notificação verificada nos serviços de saúde e a identificação de áreas (distritos sanitários) que apresentam maior risco de vir a sofrer epidemias de febre hemorrágica do dengue (FHD). Sabe-se que é mais freqüente a ocorrência de FHD, em populações previamente afetadas por epidemias de dengue clássico, fato que vai de encontro com a situação observada em São Luis.

A ocorrência de aproximadamente 401.933 infecções deve servir de alerta às autoridades estaduais de saúde do Maranhão. Uma grande população se encontra sensibilizada pelo DEN1, único sorotipo circulante até o presente na Ilha de São Luis. Se considerarmos a teoria seqüencial de Halstead, segundo a qual a FHD ocorre principalmente após epidemias de febre do dengue (FD), seguindo-se à introdução de um sorotipo diferente ao anterior 345 , poderemos ter em São Luis epidemia de FHD, se o DEN2, outros sorotipos forem introduzidos na llha de São Luis. O sorotipo DEN2 tem sido encontrado em vários estados brasileiros, inclusive no Maranhão, onde já foi isolado nos municípios de Açailândia, Balsas e Chapadinha. As atividades de vigilância e controle devem ser, portanto, implementadas para evitar a introdução do DEN2 ou outro sorotipo, prevenindo assim a FHD.

A resposta sorológica observada foi preodminantemente do tipo secundária - RS, o que provavelmente é devida a pelo menos dois fatores, quais sejam: vacinação anti-amarílica de grande parte da população e infecções prévias por outro Flavivirus especialmente pelo vírus da encefalite de Saint Louis - SLE. O vírus SLE apresentou elevada prevalência de anticorpos, fato anteriormente observado em inquérito semelhante realizado em Fortaleza, CE, mostrando que esse vírus, transmitido por diversas espécies de Culex, apresenta uma ampla distribuição pelo litoral nordestino.

Por outro lado, $58,5 \%$ da população ou 574.402 habitantes da Ilha, entre os quais 489.561 moradores do município de São Luis, ainda estava susceptível ao DEN1, quando da realização do inquérito e, portanto, sob risco de adoecer de dengue. 
Ao analisar-se os aspectos sócio-econômicos verificamos que as pessoas mais acometidas pertenciam às classes com melhor renda, apresentando prevalência maior que a média observada (Tabela 2). Fato semelhante foi observado em Fortaleza (CE), onde as causas desse fato foram atribuídas ao maior consumo de alimentos e utensílios com vasilhames descartáveis e o hábito de manter no domicílio plantas aquáticas 13 . Os mesmos fatores parecem ter relevância na situação observada na llha de São Luis. É interessante observar que os resultados obtidos em São Luis, similares aos anteriormente encontrados em Fortaleza, apresentaram uma elevada significância estatística $\left(\chi^{2}=14,48, p=0,002320\right)$. Em recente revisão dos fatores associados com a transmissão de Dengue em porto Rico6, Kuno (1995), encontrou resultados semelhantes aos encontrados em Fortaleza13 e os deste estudo na llha de São Luis.

Outro aspecto a considerar é a correlação da incidência de dengue e o grau de instrução (Tabela 3). Nesse parâmetro, observou-se uma maior prevalência da infecção por dengue a medida que aumentou o grau de instrução. Esse fato, anteriormente também observado em Fortaleza, apresentou uma elevada significância estatística $\left(\chi^{2}=20,79, p<0,0004\right)$.

Esses dados sócio econômicos e de instrução encontrados, nos permitem supor que a capacidade de entendimento dos fatores relacionados com a transmissão e os mecanismos capazes de prevenir essa transmissão são: i) mal interpretados pelas classes sócio econômicas mais favorecidas, ou ii) simplesmente essas pessoas ignoram as recomendações dos serviços de saúde, ou iii) rejeitam as visitas dos guardas da Fundação Nacional de Saúde (órgão responsável pelas operações de campo no combate ao Aedes aegypti).

No tocante à prevalência da infecção por sexo, como anteriormente observado em outras epidemias 1315 , mais uma vez não se observou significância estatística. Isto significa que embora na população estudada apresente maior número de pessoas do sexo feminino, a exposição é a mesma. Desse modo, os nossos resultados indicam que a transmissão ocorre tanto no domicílio como nos locais de trabalho.

O quadro clínico desenvolvido pela maioria das pessoas que efetivamente referiram quadro febril e outros sintomas compatíveis e apresentaram sorologia positiva foi caracterizado como dengue clássico, sem manifestações hemorrágicas. Os sintomas mais comuns, caracterizados como uma síndrome febril (Tabela 5), não diferiu daquele freqüentemente associado com dengue. Aanálise da prevalência desses sintomas não mostrou significância estatística $\left(\chi^{2}=7,22 p>0,5\right)$. Esses dados confirmam os achados de outras epidemias estudadas no Brasil 13 e em Porto Rico 16.

A estratificação da população de São Luis foi importante para visualizar melhor a distribuição das infecções por dengue nos distritos sanitários. A valorização desses dados, tende a fornecer informações acerca do maior ou menor risco de dengue hemorrágico nos diferentes distritos sanitários. Com efeito, a ocorrência de dengue não foi uniforme nos distritos, mas ao contrário, se apresentou muito heterogênea tendo a prevalência variado de $26,1 \%$ no DS3 a $56,8 \%$ DS1 (média de 41,4\%). Os dados do município de São Luis (Tabela 1), podem significar no futuro, tendo em conta a teoria da infecção seqüencial 345 , que o risco relativo de vir a ocorrer dengue hemorrágico em São Luis será muito maior nos distritos sanitários DS1, DS2 e DS3, por conta de uma exposição prévia maior (infecção por DEN1), cujos resultados apresentam significância estatística $\left(\chi^{2} 7.70, p=0,02127\right)$, do que nos demais distritos sanitários DS4, DS5, DS6 e DS7, cuja análise em separado não mostrou significância estatística $\left(\chi^{2} 3.22\right.$, $p=0,3587$ ). Foi interessante observar que nos distritos sanitários cuja população apresentava melhores condições sócio-econômicas foram os que apresentaram maiores índices de positividade. Como normalmente, essas áreas, onde mora a burguesia, apresenta melhor infra-estrutura, seria de esperar que menores índices de infecção fossem encontrados. Não foi isso, entretanto, encontrado o que permitiu-nos supor que outros fatores (não associados com infraestrutura), provavelmente, hábito de manter vasos com plantas aquáticas e o excessivo uso de descartáveis sem os cuidados no seu descarte, podem ser imputados como os principais fatores associados com a alta prevalência nesse distritos, o que aliás já fora observado em inquérito semelhante em Fortaleza, Estado do Ceará13.

Finalmente, as medidas preventivas de impacto, na vigência de um novo sorotipo de dengue na llha de São Luis devem estar voltadas com maior ênfase nos distritos sanitários DS1 a DS3, bem como, em Paço do Lumiar, que foram os locais que apresentaram as maiores taxas de positividade, conseqüentemente possuem populações mais sensibilizadas e, portanto, com maior risco de desenvolver FHD. 


\section{AGRADECIMENTOS}

Somos gratos a todos que contribuíram direta ou indiretamente para a realização do inquérito soro epidemiológico aleatório em São Luis do Maranhão, em especial ao Dr. Márcio Antônio Pinto de Almeida, Coordenador Regional da FNS no Maranhão, o Dr. Marival Pinheiro Lobão, Secretário de Estado de Saúde do Maranhão, aos técnicos do Serviço de Arbovírus do IEC Basílio Silva Buna, Iveraldo Ferreira da Silva, Maria Rute Castro Freitas e Osvaldo Vaz da Silva pelo apoio aos trabalhos de campo e de laboratório, ao inspetor Joaci Cunha da CR
FNS/MA, e finalmente às equipes da CR-FNS no Maranhão, Secretaria Estadual de Saúde e Secretaria Municipal de Saúde, que aplicaram o inquérito e que realizaram a coleta de sangue: Antônio J. Costa, David J.F. Ramos, Domingos S. Costa, José A.R. Moreno, José R.S. Araújo, José R. Gomes, José V.S. Farias, José W. Castro, Luís F.B. Santos, Júlia G. Barbosa, Keila O . Silva, Manoel S. Lopes, Maria L.N. Souza, Maryvalda M. Santos, Raimunda M. P. B. Silva, Raimundo N.C. Diniz, Raimundo N.S. Souza e Reginaldo F. Castro.

\section{REFERÊNCIAS BIBLIOGRÁFICAS}

1. Cobra C, Rigau-Pérez JG, Kuno G, Vorndam V. Symptoms of dengue fever in relation to host immunologic response and virus serotype, Puerto Rico, 1990-1991. American Journal of Epidemiology 142:1204-1211, 1995.

2. Figueiredo LTM, Cavalcante SMB, Simões MC. A dengue serologic survey of school children in Rio de Janeiro, Brazil, 1986 and 1987. Bulletin of the Panamerican Health Organization 24:217-225, 1990

3. Halstead SB. Dengue haemorrhagic fever. Apublic health problem and a field for research. Bulletin of the World Health Organization 58:1-21, 1980.

4. Halstead SB. The pathogenesis of dengue. Molecular epidemiology in infectious disease. American Journal of Epidemiology 114:632-648, 1981.

5. Halstead SB. Pathogenesis of dengue. Challenges to molecular biology. Science 239:476-481, 1988.

6. Kuno G. Review of the factors modulating dengue transmission. Epidemiology Reviews, 17:321-35, 1995

7. Ministério da Saúde. Dengue no Brasil, Fundação Nacional de Saúde, Brasília, DF, 1997.

8. Nogueira RMR, Miagostovich MP, Lampe E, Schatzmayr. Isolation of dengue type 2 in Rio de Janeiro. Memórias do Instituto Oswaldo Cruz 85:253, 1990.

9. Osanai $\mathrm{CH}$, Travassos da Rosa APA, Tang AT, Amaral RS, Passos AC, Tauil PL. Surto de dengue em Boa Vista, Roraima. Revista do Instituto de Medicina Tropical de São Paulo 25:53-54, 1983.

10. Rosa APAT, Rocha JM, Silva OV, Lins ZC. Surto de dengue em Boa Vista, território de Roraima, Brasil.
Boletim Epidemiológico (Ministério da Saúde) 14:93104, 1982

11. Schatzmayr HG, Nogueira RMR, Travassos da Rosa APA. An outbreak of dengue virus at Rio de Janeiro. Memórias do Instituto Oswaldo Cruz 81:245-246, 1986.

12. Shope RE. The use of a hemagglutination-inhibition test to follow antibody response after arthropod-borne virus infection in a community of a forest animals. Anais de Microbiologia (Rio de Janeiro) 11 (Part A):167-171, 1963.

13. Vasconcelos PFC, Lima JWO, Rosa APAT, Timbó MJ, Rosa EST, Lima HR, Rodrigues SG, Rosa JFST. Epidemia de dengue em Fortaleza, Ceará State, 1994: inquérito soro epidemiológico aleatório. Revista de Saúde Pública, 1998.

14. Vasconcelos PFC, Menezes DB, Melo LP, Pessoa ETFP, Menezes DB, Melo LP, Pessoa ETFP, Rodrigues SG, Rosa, EST, Timbó MJ, Coelho ICB, Montenegro F, Rosa JFST, Andrade FMO, Rosa APAT. A large epidemic of dengue fever with dengue hemorrhagic cases in Ceará State, Brazil, 1994. Revista do Instituto de Medicina Tropical de São Paulo 37:253-255, 1995.

15. Vasconcelos PFC, Rosa EST, Rosa JFST, Freitas RB, Dégallier N, Rodrigues SG, Rosa, APAT. Epidemia de febre clássica de dengue causada pelo sorotipo $2 \mathrm{em}$ Araguaína, Tocantins, Brasil. Revista do Instituto de Medicina Tropical de São Paulo 35:141-148, 1993. 